NASZA DERMATOLOGIA Online

OUR DERMATOLOGY Online

Source of Support: Nil

Competing Interests: None declared

\section{GOUT - INDUCED BY INFLIXIMAB?- CASE REPORT}

\author{
Anca Chiriac $^{1}$, Alice Chirana ${ }^{2}$, Anca E. Chiriac ${ }^{3}$, Ancuta Codrina ${ }^{4}$ \\ ${ }^{I}$ Nicolina Medical Center, Department of Dermtology, Iasi, Romania \\ ${ }^{2}$ Rheumatology Hospital, Department of Pathology, Iasi, Romania \\ ${ }^{3}$ University of Medicine Gr T Popa, Iasi, Romania \\ ${ }^{3}$ University of Medicine Gr T Popa, Rheumatology Clinic, Iasi, Romania \\ Corresponding author: Anca Chiriac, MD PhD \\ ancachiriac@yahoo.com
}

\begin{abstract}
Gout is a metabolic disease caused by a disturbance in purine metabolism; crystals of monosodium urate are deposited in tissues, such as joints, kidneys, and soft tissues, producing an inflammatory response. A 52-year-old woman presented in our department with 1 month history of firm, white papules, nodules and plaques over digits. She has been suffered from Rheumatoid Arthritis for many years, she has been under Infliximab therapy for more than 2 years, with good evolution of the disease. She had marked joint deformities of the proximal interphalangeal joints and slight ulnar deviation at the metacarpophalangeal joints bilaterally.
\end{abstract}

Key words: Gout; infliximab; rheumatoid arthritis

\section{Introduction}

Gout is a metabolic disease caused by a disturbance in purine metabolism; crystals of monosodium urate are deposited in tissues, such as joints, kidneys, and soft tissues, producing an inflammatory response [1].

\section{Case Report}

A 52-year-old woman presented in our department with 1 month history of firm, white papules, nodules and plaques over digits. She has been suffered from Rheumatoid Arthritis for many years, she has been under Infliximab therapy for more than 2 years, with good evolution of the disease. She had marked joint deformities of the proximal interphalangeal joints and slight ulnar deviation at the metacarpophalangeal joints bilaterally (Fig. 1).

Laboratory investigations, including full blood count, coagulation screen, serum chemistry and liver function tests, were all within normal limits. She had positive rheumatoid factor and hiperuricemia (her uric acid level was $19.2 \mathrm{mg} / \mathrm{dL}$ -normal up to 6.1).

The histopathology established the diagnosis : the presence of an amorphous material in the dermis, formed by aggregates of urate crystals, surrounded by an inflammatory reaction consisting of macrophages, lymphocytes, and giant cells (Fig. 2, 3).

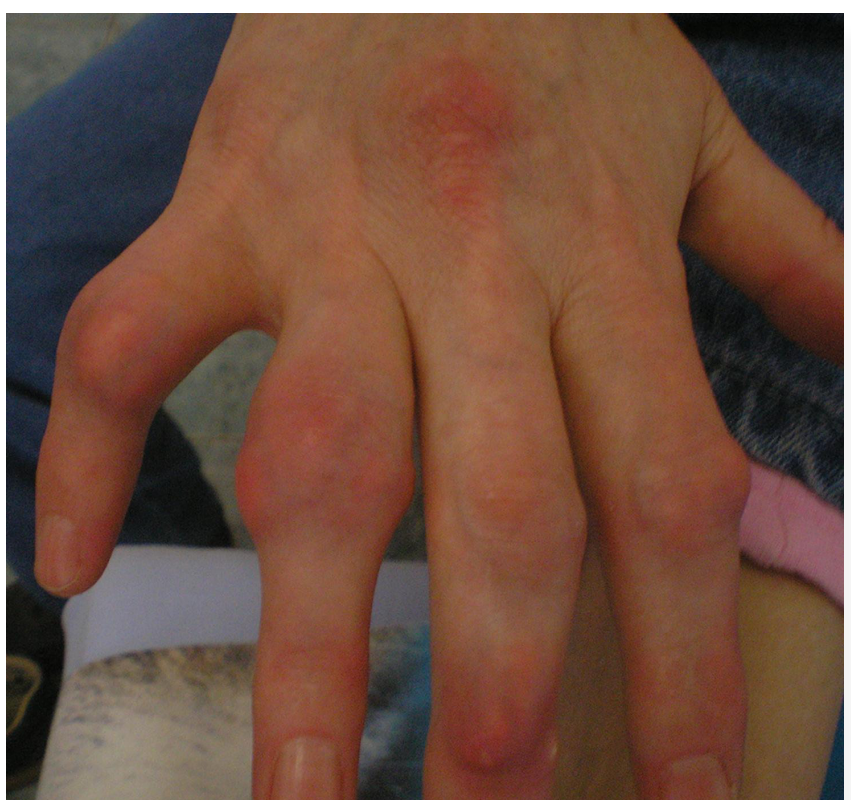

Figure 1. 52-year-old woman with nodules and plaques 


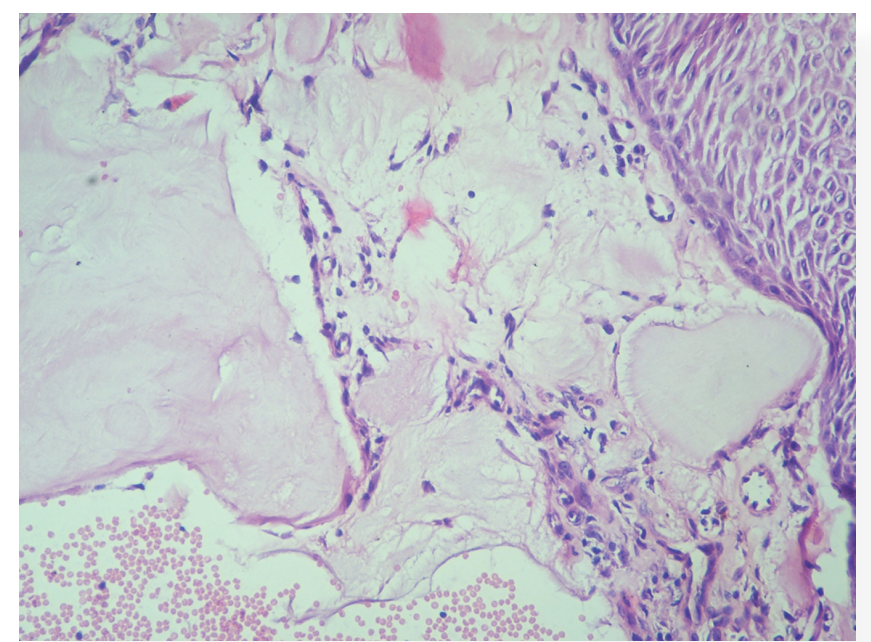

Figure 2. Histopathological aspects of the lesion

\section{Discussion}

In this case tophi were presented as nodules at the distal interphalangeal joints, dorsal aspect of the proximal interphalangeal and metacarpophalangeal joints and toes. They arised in a postmenopausal woman (as they usually do, because of the absence of the protective effect of estrogen on acid uric level), with no previous signs of gout. Tophi had a progressive evolution over a few months, with a spontaneous drainage and a subsequent ulceration on the toe.

Among the risk factors for gout, in this case, we could not include: alcohol intake, use of thiazide diuretics, renal dysfunction or hypertension; but we thought of Infliximab as a risk factor [2].

The differential diagnosis included calcium pyrophosphate deposition disease (pseudogout), calcinosis cutis, and rheumatoid or cholesterol nodules $[3,4]$, but the diagnosis of gout was strongly considered on the clinical, histopathological grounds corelared with the hiperuricemia. The risk of gout increases with increasing hyperuricemia, although serum uric acid levels may be elevated without clinical evidence

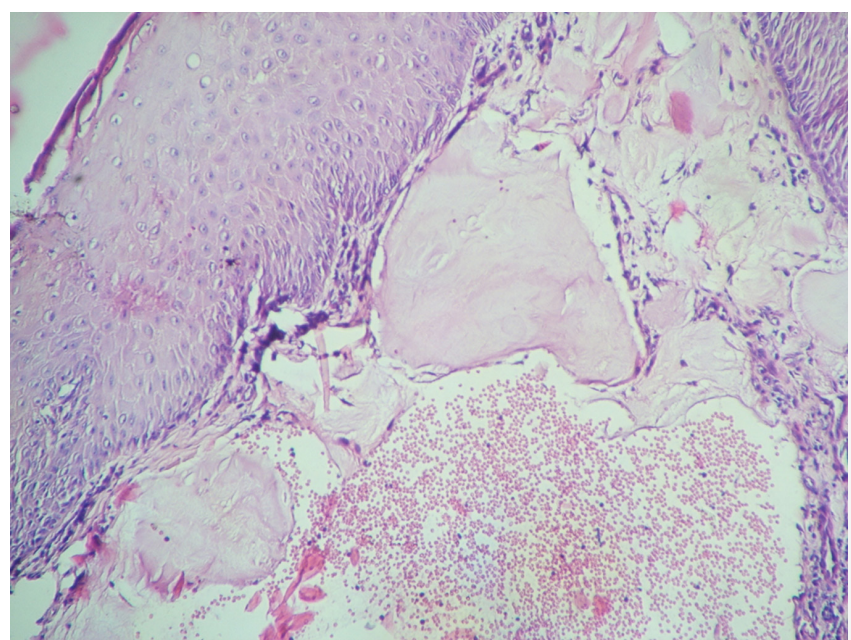

Figure 3. Histopathological aspects of the lesion

of gout [3].

Although many medications also favor this condition, such as low-dose aspirin, cyclosporine, ethambutol, pyrazinamide, ritonavir, levodopa, and nicotinic acid [4], we consider that it is the first case reported in the literature as gout induced by Infliximab in a patient with Rheumatoid Arthritis, taking into considerations that Infliximab is a therapy of choise in chronic tophaceous gout [5].

\section{REFERENCES}

1. Thissen CACB, Frank J, Lucker GPH: Tophi as first clinical sign of gout. Int J Dermatol. 2008;47(Suppl. 1):49-51.

2. Kling CW, Helm TN, Narins RB: Photo quiz. Intradermal tophaceous gout. Cutis. 2001;196:205-6.

3. Eggebeen AT: Gout: an update. Am Fam Physician. 2007;76:8018.

4. Falasca GF: Metabolic diseases: Gout. Clin Dermatol. 2006;24:498-508.

5. Fiehn C, Zeier M: Successful treatment of chronic tophaceous gout with infliximab (Remicade). Rheumatol Int. 2006;26:274-6.

Copyright by Anca Chiriac, et al. This is an open access article distributed under the terms of the Creative Commons Attribution License, which permits unrestricted use, distribution, and reproduction in any medium, provided the original author and source are credited. 